\title{
Preface The Global Invasive Species Program (GISP)*
}

\section{Harold A. Mooney}

During the period between 1982 and 1988 the Scientific Committee on Problems of the Environment (SCOPE) engaged a large number of scientists in an effort to document the nature of the invasive species 'problem'. The results of this effort appeared in a number of books and as a synthesis in 1989 entitled Biological Invasions: A Global Perspective (Drake et al., 1989). This synthesis clearly established that invasive species could have major impacts on ecosystem functioning and that virtually all ecosystems were impacted by them, even those under preservation management. It was also clear that we are on the way to establishing a whole new biotic order on the Earth due to the massive breakdown of biogeographic barriers to migration. Although the SCOPE programme was quite successful scientifically it did not offer much to managers except to inform them they were not alone in the world dealing with these problems.

SCOPE, along with partners from UNEP (United Nations Environment Program), IUCN (International Union for the Conservation of Nature) and CABI (Commonwealth Agricultural Bureau International), is embarking on a new programme on invasive species, this time with the explicit objective of providing new tools for understanding as well as dealing with invasive species. This venture is called the Global Invasive Species Program, or GISP. This effort differs substantially from the previous programme in that it will engage the many constituencies that are involved with the problem including natural and social scientists, educators, lawyers, resource managers, and people from both industry and government.

The programme has 11 elements. Each of these will contribute to building the comprehensive approach that is needed for dealing with invasive species. Four elements deal with synthesizing our current knowledge on invasive species. These include the ecology of invasive species (led by David Richardson

* This preface appeared in Biological Invasions, 1: 97-8, 1999. Reprinted here with kind permission from Kluwer Academic Publishers. 
and Marcel Rejmánek), the current status of invasive species and new methods for assessing their changing distributions and abundance (Mark Lonsdale and Richard Mack), how society views and values invasive species (Jeff McNeely) and how global change will impact the success of invaders (Richard Hobbs and Harold Mooney).

A major effort of GISP will be the development of new tools and approaches for dealing with invasives. These include the development of a global early warning system for the most serious invasive species (Mick Clout), an analysis of the changing pathways of trade as they provide vectors for invasives (James Carlton and Greg Ruiz), new approaches for developing risk analyses dealing with the introduction of new biotic material into ecosystems (David Andow), assessment of the best practices for management and control of invasives (Jeff Waage), the development of new approaches for educating the general public on the potential dangers of invasive species (Alan Holt), the economic consequences of invasive species (Charles Perrings and Mark Williamson), and an analysis of the legal and institutional frameworks for dealing with invasives (Lyle Glowka).

All of these elements will have one or more workshops with specific products. All of these activities will be synthesized at a summary workshop in Capetown, South Africa, in September 2000.

Whereas the original SCOPE project was satisfied with production of a scientific synthesis volume as a final product, GISP has much broader objectives. The focus is on the production of new tools, the evaluation of best management practices, and the articulation of a new strategy for addressing the issues. Specific products would include management and educational packages, summaries for policy makers, and importantly, a popular volume describing all that was learned during this programme.

Post-GISP efforts would put this strategy into action. GISP is funded by the Global Environment Facility (GEF), UNEP, the United Nations Educational, Scientific, and Cultural Organization (UNESCO), the National Aeronautics and Space Administration (NASA), the International Council for Science (ICSU), La Fondation Total, the John T. and Catherine D. MacArthur Foundation, and the Norwegian government.

For more information about GISP contact Véronique Plocq-Fichelet, SCOPE Secretariat, 51, bd de Montmorency, 75016 Paris, France (e-mail: scope@paris7jussieu.fr). The Website is http://jasper.stanford.edu/GISP/.

\section{REFERENCE}

Drake, J.A., H.A. Mooney, F. di Castri, R.H. Groves, F.J. Kruger, M. Rejmánek and M. Williamson (eds) (1989), Ecology of Biological Invasions: A Global Perspective, SCOPE 37, New York: John Wiley. 